\title{
Characterization of the Microstructure and Electrical Conductivity of Plasma-Sprayed $\mathrm{La}_{0.5} \mathrm{Sr}_{0.5} \mathrm{CoO}_{3}$ Coating
}

\author{
Cheng-Xin Li, Min Gao, Chang-Jiu Li*, Wei Zhou, Guan-Jun Yang and Yu-Yue Wang \\ State Key Laboratory for Mechanical Behavior of Materials, School of Materials Science and Engineering, \\ Xi'an Jiaotong University, Xi'an, Shaanxi, 710049, P. R. China
}

Lanthanum strontium cobalt oxide (LSCO) has been employed as cathode and intercollector materials for solid oxide fuel cells (SOFCs). In the present study, the $\mathrm{La}_{0.5} \mathrm{Sr}_{0.5} \mathrm{CoO}_{3}$ layer was deposited by atmospheric plasma spray (APS). The effect of heat treatment on microstructure and electrical conductivity of the LSCO deposits was examined. The electrical conductivity of the deposits along the lamellar direction was measured by a four-probe dc approach. The microstructure of the deposit was characterized by scanning electron microscopy and X-ray diffraction analysis. The results showed that the electrical conductivity of plasma-sprayed LSCO coating was lower than that of sintered bulk material with the same composition. The minor metastable phase in the as-sprayed coating reduced the electrical conductivity. The annealing treatment at $1000^{\circ} \mathrm{C}$ led to the elimination of the metastable phase and improved the electrical conductivity. The lamellar structure features with the limited interface bonding limits the electrical conductivity. [doi:10.2320/matertrans.47.1654]

(Received November 30, 2005; Accepted April 24, 2006; Published July 15, 2006)

Keywords: lanthanum strontium cobalt oxide, electrical conductivity, plasma spraying, coating, solid oxide fuel cell

\section{Introduction}

Lanthanum strontium cobalt oxide (LSCO) has been intensively investigated as they are widely applied to hightemperature ionic devices such as solid oxide fuel cells (SOFCs), oxygen monitors, and gas-separation membranes for its high electronic conductivity. ${ }^{1-3)}$ In the case of SOFC, the perovskite system $\mathrm{La}_{1-\mathrm{x}} \mathrm{Sr}_{\mathrm{x}} \mathrm{CoO}_{3}$ has been demonstrated to give an excellent cathode performance with a very low overpotential even at a high current density. ${ }^{4)}$ However, high thermal expansion coefficient of LSCO system leads to a significant thermal expansion mismatch between LSCO electrode and electrolyte. Moreover, the LSCO reacts with $\mathrm{ZrO}_{2}$ electrolyte at high temperature resulting in insulating layer. Those features make LSCO system not be suitable for using as a cathode material directly. On the other hand, LSCO can be used as cathode current collector through a multi-layered cathode ${ }^{5)}$ to reduce ohmic loss in the cathode in SOFC.

Various preparation techniques, such as sol-gel method, ${ }^{6}$ slurry coating, ${ }^{7)}$ and pulsed laser deposition, ${ }^{8)}$ have been employed to manufacture LSCO layer. However, those processes are often relatively expensive or time-consuming. On the other hand, atmospheric plasma spraying (APS) would be a promising processing route because of its fast deposition rate and easy masking for deposition of patterned structures. During plasma spraying, particles in a size of tens micrometers will be heated to a fully or partially melted state. After molten droplet impacts on a substrate, it experiences a rapid cooling and solidification. This thermal cycling may lead to the microstructure of subsequent coating different from that of the starting powder. Moreover, reduction atmosphere of high temperature plasma jet generated by Ar with an addition of $\mathrm{H}_{2}$ may lead to the change of composition and microstructure of LSCO from powder to coating. However, few papers were concerned with microstructural

*Corresponding author, E-mail: licj@mail.xjtu.edu.cn features of plasma-sprayed LSCO coatings.

In this paper, the LSCO powders with a composition of $\mathrm{La}_{0.5} \mathrm{Sr}_{0.5} \mathrm{CoO}_{3}$ were synthesized, and the LSCO coating was deposited by APS. The microstructure and electrical conductivity of the LSCO deposit were characterized. The effect of LSCO microstructure on the electrical conductivity was examined.

\section{Materials and Experimental}

$\mathrm{La}_{0.5} \mathrm{Sr}_{0.5} \mathrm{CoO}_{3}$ was prepared by a conventional solid phase reaction process using a mixture of $\mathrm{La}_{2} \mathrm{O}_{3}, \mathrm{Sr}\left(\mathrm{NO}_{3}\right)_{2}$, and $\mathrm{Co}\left(\mathrm{NO}_{3}\right)_{2} \cdot 6 \mathrm{H}_{2} \mathrm{O}$. The mixed powder was sintered at $1200^{\circ} \mathrm{C}$ for 24 hours in an ambient atmosphere and then sintered at $1400^{\circ} \mathrm{C}$ for 10 hours. The sintered powders were then crushed and sifted to a proper particle size range for spraying. LSCO coatings were prepared by a commercial plasma spraying system (GDP-80, $80 \mathrm{~kW}$ class, JIUJIANG) under the plasma power of $30 \mathrm{~kW}$ at the spray distance of $100 \mathrm{~mm}$. An $\mathrm{Ar} / \mathrm{H}_{2}$ plasma was used to melt and accelerate powders. Argon and hydrogen were supplied at pressures of 0.8 and $0.4 \mathrm{MPa}$, respectively. The flow rate of argon was fixed to $47 \mathrm{l} / \mathrm{min}$. The free standing specimens with dimensions of $20 \mathrm{~mm}$ in length and $8 \mathrm{~mm}$ in width and approximately $700 \mu \mathrm{m}$ in thickness were produced for electrical conductivity measurement. The crystalline structure of both powder and deposited coating was characterized by X-ray diffraction analysis (XRD) (Rigaku D/max-2400). Scanning electron microscope (SEM) was employed to characterize the microstructure of the coatings. The electrical conductivity of the specimen along the lamellar direction was measured by a four-probe dc approach.

\section{Results and Discussions}

3.1 Microstructure of plasma-sprayed LSCO coatings XRD pattern of plasma-sprayed LSCO coating is shown in Fig. 1 in comparison with that of LSCO powder and the 


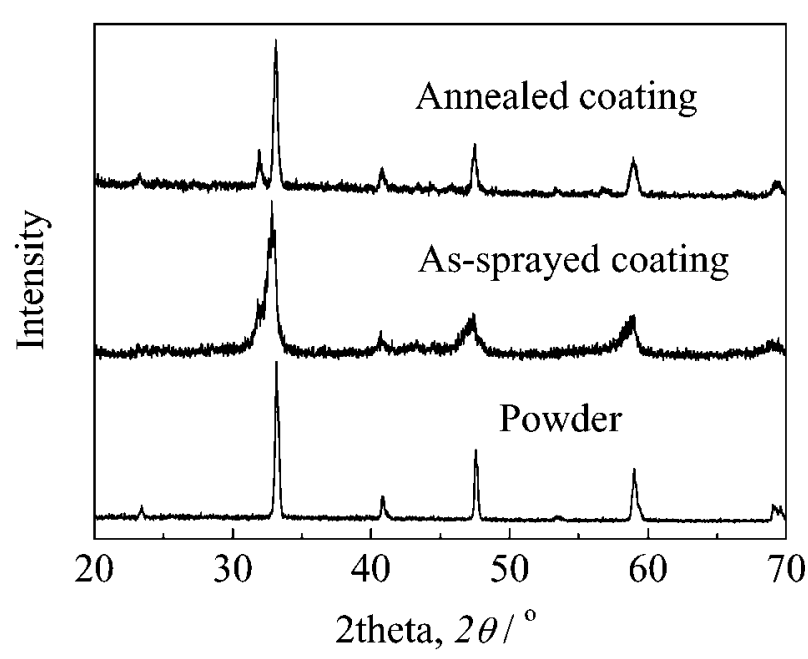

Fig. 1 XRD pattern of the as-sprayed LSCO coating in comparison of that of the starting powder and annealed coating.

annealed coating. The powder clearly presented a wellcrystallized perovskite phase. After spraying, although XRD peaks were noticeably broadened, XRD spectrum of the assprayed LSCO coating was comparable to that of the assynthesized LSCO powder. This fact means that the coating was also crystallized in perovskite phase. A little shift of XRD peaks suggested the occurrence of certain distortion of lattice in the as-sprayed coating. A thermal spray coating is generally deposited through rapid splat cooling process. The high cooling rate over $10^{5} \mathrm{~K} \cdot \mathrm{s}^{-1}$ usually results in formation of metastable phases in the coating. ${ }^{9)}$ The broadening of XRD peaks implies that the fine crystalline grains were present in the as-sprayed coating. From the XRD pattern of LSCO coating annealed at $1000^{\circ} \mathrm{C}$ for 20 hours, it is clear that after annealing treatment, the coating presents the same perovskite phase as that of the starting powder. The width of XRD peaks decreased after annealing treatment compared with that of assprayed one. This fact suggests that the crystallinity and grain size increased. It is also found that one unknown peak appeared in XRD pattern after annealing, although the identification is necessary in further study.

The examination of a cross-sectional microstructure clearly shows that a lamellar microstructure was presented in the as-sprayed LSCO coating as shown in Fig. 2(a). This fact means that the coating was deposited by sufficiently melted spray particles. The limited large voids observed on the cross-section were possibly resulted from the pulling out of ceramic particle fractions owing to limited bonding between lamellar interfaces. It can be observed from the fractured cross section (Fig. 2(b)) that there existed lamellar interface cracks, which is referred to as non-bonded interface area.

Figure 3 shows SEM micrograph of the fractured LSCO coating after annealing at $1000^{\circ} \mathrm{C}$ for 20 hours. No significant change of the lamellar microstructure was observed in comparison with the as-sprayed LSCO coating as shown in Fig. 2(b). The coating clearly presents a lamellar microstructure. It can be observed that there existed non-bonded interface areas between lamellar interfaces. The lamellar structure features of thermal spray coating with limited (a)

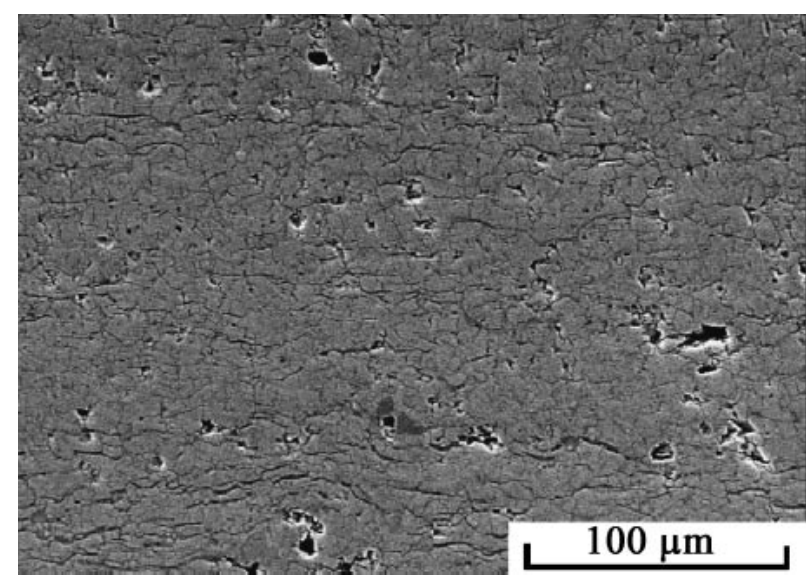

(b)

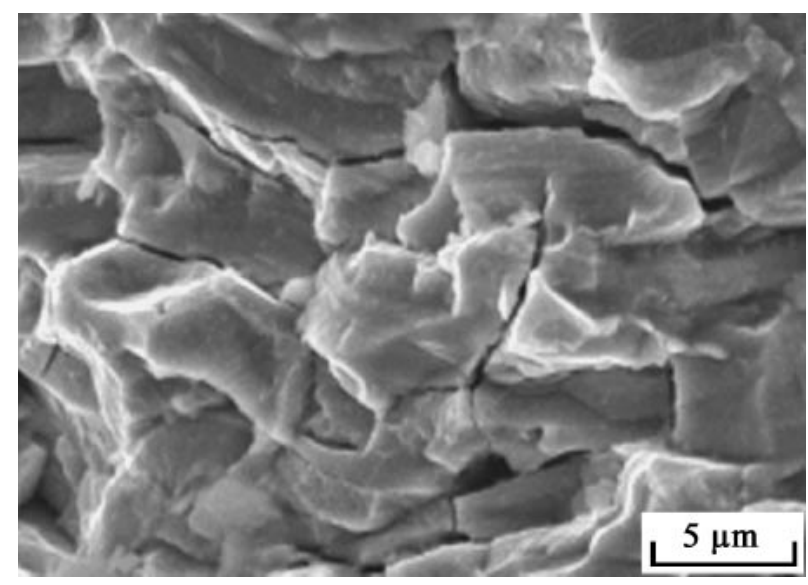

Fig. 2 Polished (a) and fractured (b) cross sectional morphology of the assprayed LSCO coating.

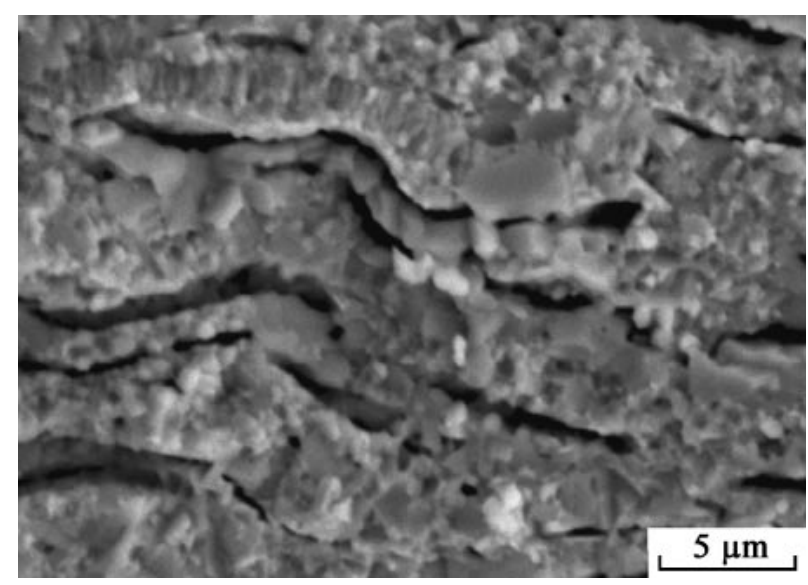

Fig. 3 Fractured cross sectional morphology of the LSCO coating annealed at $1000^{\circ} \mathrm{C}$ for 20 hours.

lamellar interface bonding lead to the anisotropy of coating properties and the reduction of electrical conductivity. ${ }^{10)}$

\subsection{Electrical conducting behavior of the as-sprayed LSCO coating}

The dependency of the electrical conductivity of the as- 


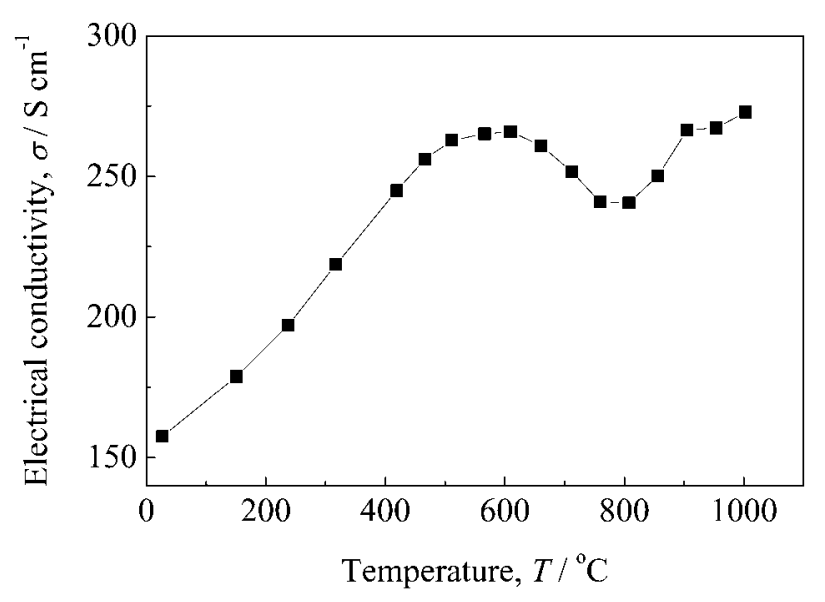

Fig. 4 Influence of temperature on the electrical conductivity of the assprayed LSCO coating.

sprayed LSCO coatings on measurement temperature is plotted in Fig. 4. Because the ionic transport number in LSCO is low (typically less than $1 \%^{11)}$ ), the conductivity obtained by the dc four-probe approach represents essentially the electronic conductivity of the material. At a temperature range from room temperature to about $600^{\circ} \mathrm{C}$, the conductivity increased with increasing temperature. The electrical conductivity tended to decrease as temperature was above $600^{\circ} \mathrm{C}$. However, the electrical conductivity of LSCO coating increased again as the temperature was raised above $800^{\circ} \mathrm{C}$

$\mathrm{LaCoO}_{3}$ bulk behaves as a semiconductor at lower temperature and the conductivity has a positive temperature coefficient. At high temperature range the conductivity becomes less temperature dependent. ${ }^{12)}$ The dependency of $\mathrm{La}_{1-\mathrm{x}} \mathrm{Sr}_{\mathrm{x}} \mathrm{CoO}_{3}$ on temperature at low temperature changes with substituting $\mathrm{Sr}$ for La. But, at high temperature, especially above $600^{\circ} \mathrm{C}$, the dependency of electrical conductivity of $\mathrm{La}_{1-\mathrm{x}} \mathrm{Sr}_{\mathrm{x}} \mathrm{CoO}_{3}$ on temperature presents a negative temperature coefficient in a way similar to metallic alloy. $^{12-14)}$

The result shown in Fig. 4 reveals that the as-sprayed LSCO coating presents a different temperature dependency from that observed for sintered LSCO bulk. This fact can be attributed to the microstructure change during the measurement at high temperature as revealed in following section.

\subsection{Effect of annealing treatment on electrical conduc- tivity of the LSCO coatings}

The change of electrical conductivity of plasma-sprayed LSCO coating with annealing time at $1000^{\circ} \mathrm{C}$ is shown in Fig. 5. It can be found that the electrical conductivity of the LSCO coating increased with the increase of annealing time and reached to a saturated level as the annealing time was over 16 hours. The maximum electrical conductivity at $1000^{\circ} \mathrm{C}$ was about $377 \mathrm{~S} \cdot \mathrm{cm}^{-1}$. Therefore, after annealing at $1000^{\circ} \mathrm{C}$ for 20 hours, the electrical conductivity was increased by about $40 \%$.

Relationship between the electrical conductivity and temperature for LSCO coating annealed at $1000^{\circ} \mathrm{C}$ is shown in Fig. 6. It can be found that the electrical conduction of the annealed plasma-sprayed LSCO coating behaves as a semi-

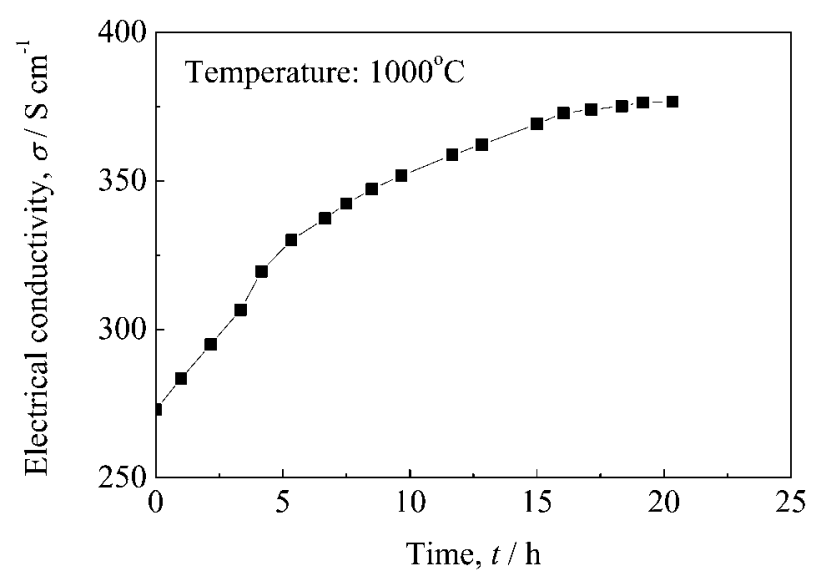

Fig. 5 Influence of annealing time on the electrical conductivity of LSCO coating at $1000^{\circ} \mathrm{C}$.

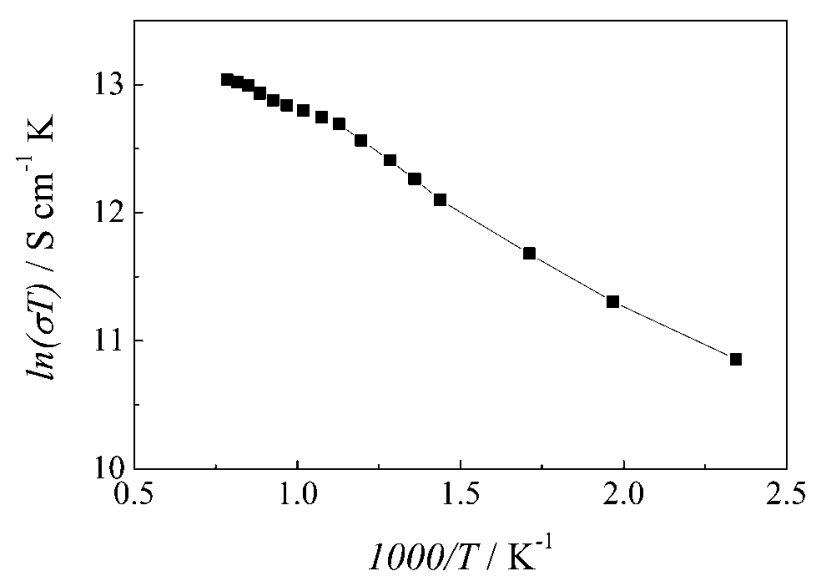

Fig. 6 Relationship between the electrical conductivity and temperature for LSCO coating annealed at $1000^{\circ} \mathrm{C}$.

conductor at the temperature range tested in present study, although the electrical conductivity becomes less temperature dependent at temperature range higher than $600^{\circ} \mathrm{C}$. The activation energy $\left(E_{\mathrm{a}}\right)$ for hopping of the small polarons was calculated from the slopes of the linearly fitted line between $\ln (\sigma T)$ and $1 / T$. The activation energy of the annealed coating was about $8.9 \mathrm{~kJ} \cdot \mathrm{mol}^{-1}$ at the temperature higher than $600^{\circ} \mathrm{C}$, while it increased to about $12.7 \mathrm{~kJ} \cdot \mathrm{mol}^{-1}$ at the temperature lower than $600^{\circ} \mathrm{C}$.

It is interesting that the electrical conductivity at temperatures higher than $600^{\circ} \mathrm{C}$ presents a positive temperature coefficient, while sintered $\mathrm{La}_{\mathrm{x}} \mathrm{Sr}_{1-\mathrm{x}} \mathrm{CoO}_{3}$ bulk usually presents a negative temperature coefficient of electrical conductivity. This feature of plasma-sprayed LSCO is more favorite for SOFC operation at high temperature, although the mechanism resulting in this characteristic is unknown at present.

\subsection{Effect of microstructure on the electrical conduc- tivity of plasma-sprayed LSCO coating}

Plasma-sprayed coating usually presents a lamellar structure. The porosity from several up to around $20 \%$ is usually present in ceramic coatings. ${ }^{15}$ ) The porosity of coating depends significantly on spray conditions. The study into the 
lamellar interface bonding revealed that only a very limited lamellar interface is bonded together. The nonbonded interface area exceeds two-thirds of total apparent interface. ${ }^{16-18)}$ There are also microcracks in individual ceramic splat in the coating.

Owing to the lamellar structure feature with limited interface bonding, the thermal conductivity ${ }^{18)}$ and electrical conductivity is much less than identical bulk material. ${ }^{10,19)}$ Moreover, plasma-sprayed coating obviously presents an anisotropy in electrical conductivity. The previous study revealed that the electrical conductivity of ceramic coating along the direction perpendicular to the coating surface was one-fifth to one-third that of corresponding bulk materials. ${ }^{11,19)}$ The electrical conductivity along the lamellar direction is higher than that perpendicular to the lamellar direction. The electrical conductivity parallel to the lamellar direction of plasma-sprayed YSZ coating was reached onehalf of corresponding bulk materials. ${ }^{20)}$

Mineshige et al. reported an electrical conductivity of about $750 \mathrm{~S} \cdot \mathrm{cm}^{-1}$ at $1000^{\circ} \mathrm{C}$ for a sintered bulk $\mathrm{La}_{0.5} \mathrm{Sr}_{0.5^{-}}$ $\mathrm{CoO}_{3},{ }^{12)}$ while the maximum electrical conductivity of the annealed plasma-sprayed LSCO was about $377 \mathrm{~S} \cdot \mathrm{cm}^{-1}$ at $1000^{\circ} \mathrm{C}$ as shown in Fig. 5. This fact clearly indicates that the electrical conductivity of plasma sprayed at the direction parallel to lamella is about half of sintered bulk. The result is consistent with those previous findings. ${ }^{20}$ ) It has been reported that deficiency of oxygen in the lattice of LSCO influences significantly the electrical conductivity. ${ }^{21)}$ It was also found that although the starting powder has a stoichiometrical composition of $\mathrm{La}_{0.5} \mathrm{Sr}_{0.5} \mathrm{CoO}_{3}$ in this study, the deficiency of oxygen occurred to plasma-sprayed LSCO coating. This may be due to high temperature of $\mathrm{Ar}-\mathrm{H}_{2}$ plasma jet with certain reduction atmosphere. The influence of this effect on electrical conductivity of plasma-sprayed coating is under investigation. However, it was also found that the recovery of deficient oxygen occurs during annealing treatment. Therefore, the low electrical conductivity of plasma-sprayed coating compared with sintered bulk is mainly dominated by lamellar structure and bonding condition between lamellae in the coating.

\section{Conclusions}

Plasma-sprayed LSCO coating presented a typical lamellar structure. XRD result suggests existance of metstable crystalline in the perovskite structure. The dependency of electrical conductivity of plasma-sprayed LSCO on temperature was different from that of sintered bulk owing to unstable phase. The annealing treatment for the as-prayed
LSCO coating at $1000^{\circ} \mathrm{C}$ removed the metastable microstructure and improved the electrical conductivity. The electrical conductivity of the annealed LSCO coating was about $377 \mathrm{~S} \cdot \mathrm{cm}^{-1}$ at $1000^{\circ} \mathrm{C}$. It was about one-half of that of sintered one. This fact suggests that the lamellar structure feature with the limited interface bonding mainly dominates the electrical conductivity in the APS coating besides the microstructure of lamella itself. It was found that the annealed plasma-sprayed LSCO coating behaves as a semiconductor with a positive temperature coefficient of electrical conductivity at the measured temperature range. This characteristic is more favorite for SOFC operating at high temperature than the negative temperature coefficient of electrical conductivity observed for bulk LSCO.

\section{REFERENCES}

1) J. A. Kilner, R. A. de Souza and I. C. Fullarton: Solid State Ionics 8688 (1996) 703-709.

2) B. C. H. Steele: Solid State Ionics 75 (1995) 157-167.

3) N. Q. Minh: J. Am. Ceram. Soc. 76 (1993) 563-568.

4) R. Zheng, X. M. Zhou, S. R. Wang, T.-L. Wen and C. X. Ding: J. Power Sources 140 (2005) 217-225.

5) J.-H. Kim, R.-H. Song, K.-S. Song, S.-H. Hyun, D.-R. Shin and H. Yokokawa: J. Power Sources 122 (2003) 138-143.

6) R. Chiba, F. Yoshimura, Y. Sakurai, Y. Tabata and M. Arakawa: Solid State Ionics 175 (2004) 23-27.

7) S.-D. Kim, S.-H. Hyun, J-. Moon, J.-H. Kim and R.-H. Song: J. Power Sources 139 (2005) 67-72.

8) X. Chen, N. J. Wu, D. L. Ritums and A. Ignatiev: Thin Solid Films 342 (1999) 61-66.

9) R. McPherson: J. Mater. Sci. 8 (1973) 851-858.

10) C.-J. Li, X.-J. Ning and C.-X. Li: Surf. Coat. Technol. 190 (2005) 6065.

11) Y. Teraoka, H. M. Zhang, K. Okamoto and N. Yamazoe: Mat. Res. Bull. 23 (1988) 51-58.

12) A. Mineshige, M. Inaba, T. Yao, Z. Ogumi, K. Kikuchi and H. Shiga: J. Solid State Chem. 121 (1996) 423-429.

13) A. Petric, P. Huang and F. Tietz: Solid State Ionics 135 (2000) 719725.

14) J. W. Stevenson, T. R. Armstrong, R. D. Carneim, L. R. Rederson and W. J. Weder: J. Electrochem. Soc. 143 (1996) 2722-2729.

15) C.-J. Li, A. Ohmori and R. McPherson: J. Mater. Sci. 32 (1997) 9971004.

16) A. Ohmori, C.-J. Li and Y. Arata: Trans. Jpn. Weld. Res. Inst. 19 (1990) 259-270.

17) A. Ohmori and C.-J. Li: Thin Solid Films 201 (1991) 241-252.

18) C.-J. Li and A. Ohmori: J. Therm. Spray Technol. 11 (2002) 365-374.

19) C.-J. Li, C.-X. Li and M. Wang: Surf. Coat. Technol. 198 (2005) 278282.

20) Q. Schiller, R. H. Henne, M. Lang, R. Ruckdaschel and S. Schaper: Fuel Cell Bulletin 21 (2000) 7-12.

21) H. Ullmann, N. Trofimenko, F. Tietz, D. Stover and A. AhmadKhanlou: Solid State Ionics 138 (2000) 79-90. 